\title{
Effect of Material Properties on Core Loss in Switched Reluctance Motor using Non-Oriented Electrical Steels
}

\author{
J. Kartigeyan ${ }^{1 *}$ and M. Ramaswamy ${ }^{2}$ \\ ${ }^{1,2}$ Department of Electrical Engineering, Annamalai University, Tamil Nadu - 608002, India
}

(Received 10 November 2016, Received in final form 18 February 2017, Accepted 20 February 2017)

\begin{abstract}
The effort attempts to investigate the influence of various non-oriented electrical steel sheets on the core loss of a switched reluctance motor (SRM). The core loss of the motor inherits a strong correlation with flux density and permeability of the material. The study involves the use of laminated $2.7 \%$ high silicon steel suitable for the motor in view of its higher flux density and lower core loss. The accurate prediction of core loss leaves way to suggest measures for improving the performance of the SRM. The dynamic simulation measurements of a $1.5 \mathrm{~kW}$, three-phase 12/8 SRM involve the finite element method (FEM) and use the data obtained experimentally from Epstein frame. The closeness of the simulated and hardware results obtained with laminations of M400-50A, DI MAX-M19 and DI MAX-M15 both for the stator and rotor, espouse a greater significance to the findings in terms of the core loss density and forge new dimensions for its use in the drive industry.
\end{abstract}

Keywords : core loss, non-oriented electrical steels, relative permeability, switched reluctance motor

\section{Introduction}

The electric motor drives appear to use around $70 \%$ of the power demand from the industries [1] to support the emerging automated environment. However the energy scarce scenario and clean energy enforcements augur an efficient use of electric energy in the motor systems.

The advancements in the power electronics technology enable the affordable nature of the variable-speed drives and offer resurgence to the use of hybrid vehicles. Among a host of drive motors the switched reluctance motor (SRM), owing to its exclusive features such as lack of any coil or permanent magnet on the rotor continue to occupy a pre-eminent place.

The use of silicon steel in the stator winding allows recycling and ensures a higher reliability for the operation of SRM in hard or sensitive conditions [2-4]. Besides the salient rotor structure produces a high torque/inertia ratio to guarantee a fast acceleration and deceleration with low load inertia. Despite the recent developments in the design and application of the SRM [5-9], the cost and supply of rare-earth permanent magnets poses a problem for future mass production.

(C)The Korean Magnetics Society. All rights reserved.

*Corresponding author: Tel: +91-9442692710

Fax:+91-4144-238275, e-mail: j.kartigeyan@gmail.com
The reports reveal that the SRM can be designed to be competitive with permanent magnet brushless dc motors from the standpoint of efficiency [10]. The use of $6.5 \%$ $\mathrm{Si}$ steel with $0.10 \mathrm{~mm}$ thickness for the core material appears to be the primary reason for enabling the loss reduction and achieving a higher efficiency. It thus becomes important to use proper electrical steel sheets as material for the core [11] and gathers merit to predict the motor core loss reliably. It turns out to be imperative for estimating the dependence of the motor core loss on the typical magnetic properties in terms of the choice of the core material.

The magnetic cores for the low-voltage ac electric motors, drawn from cold rolled non-oriented (CRNO) electrical steel sheets $[12,13]$ classify themselves as soft ferromagnetic materials produced from $\mathrm{Fe}-\mathrm{Si}-\mathrm{C}$ alloys. The cold rolled non oriented electrical steel sheets with nearly isotropic magnetic properties enjoy restricted silicon levels to about 3.0-3.5 \% due to rolling behavior [12]. The issue of the core losses prediction in CRNO steel sheets invites attention for the designers of magnetic cores [14].

The design of a SRM with a rotor consisting of two hollow iron cylinders and a stator excited in a way that allows a one directional current flow to minimize the core losses has been discussed in [15]. The core losses and efficiency of the SRM in continuous current mode of 
operation has been predicted using analytical technique by Amir Parsapour et al. [16]. The core losses have been computed in different parts of the SRM using FEM (Finite Element Method) and Transient-FEM in [17, 18] respectively. The effect of dynamic eccentricity (DE) and static eccentricity (SE) on the power losses of the induction machines has been examined using PWM voltage control by 2D-FEM [19].

In spite of the related studies, still it calls for efforts to reduce the core losses of the electric motors in a perspective to improve its magnetic circuit performance and assuage a higher operational efficiency. The primary effort extends to examine the choice of proper electrical steel sheets as core material [19] and facilitate to predict the motor core loss reliably at the design stage. The key feature corners to reduce the core loss of the motor and allow it perform to the best of its capability. The procedure involves stages of simulation and experimental validation to foresee a path for enhancing the performance of the motor. The theory relates to the study of the influence of material magnetic properties on the motor core loss of a 12/8 (12 teeth on stator and 8 teeth on rotor) SRM using various non-oriented steels for the core material.

\section{Specification and Iron Material}

\subsection{Specification}

The exercise relies on building the core loss model based on the SRM lamination shapes and dimensional parameters in Table 1 to investigate the influence of electrical steel sheets on the magnetic characteristics and the core loss. It involves varying the material of iron core (both stator core and rotor core) with the other specifications kept consistent. The motor models tested by

Table 1. Specification of SRM.

\begin{tabular}{lc}
\hline \hline Item & Specification \\
\hline No. of phases & 3 \\
D.C link voltage $(\mathrm{V})$ & 72 \\
No. of stator/rotor poles & $12 / 8$ \\
Stator outer diameter $(\mathrm{mm})$ & 120 \\
Stator yoke thickness $(\mathrm{mm})$ & 11 \\
Stator-rotor gap $(\mathrm{mm})$ & 0.3 \\
Rotor outer diameter $(\mathrm{mm})$ & 70 \\
Rotor yoke thickness $(\mathrm{mm})$ & 08 \\
Shaft diameter $(\mathrm{mm})$ & 30 \\
Stator steel weight $(\mathrm{kg})$ & 4.6 \\
Rotor steel weight $(\mathrm{kg})$ & 2.5 \\
Torque $(\mathrm{N}-\mathrm{m})$ & 2.8 \\
Speed $(\mathrm{r} / \mathrm{min})$ & 5100 \\
\hline
\end{tabular}

experiment as seen from Fig. 12 depend on using the progressive die to manufacture the iron cores by the automatic lamination process.

\subsection{The Laminated Electrical Steel}

The non-oriented steel belongs to a special class of silicon steel with $2.7 \%$ silicon, $0.003 \%$ carbon, $0.15 \%$ manganese, $0.01 \%$ phosphorus, $0.001 \%$ sulfur, in which the magnetic properties remain uniform in all the angular directions. It inherits high permeability and low coercivity, which enables to realize higher strengths of induction on the application of a lower intensity field and result in lower magnetic losses [20]. The factors like higher induction and stronger permeability owe to reduce the size and weight of the parts of the motor. Consequently it serves to increase the efficiency; lower the magnetic losses and reduce the generation of heat energy. It thus helps in minimizing the energy consumption, besides the lower coercivity helps in producing less humming sound in machines.

The arrangement interfaces a $700 \times 700$ turn standard Epstein tester with the system to measure magnetic permeability and core loss over a wide range of frequencies in induction increments of 0.05T. The excitation and measurement system involves a crystal accurate 16 bit sine wave generator, which provides $25 \mathrm{~Hz}$ to $450 \mathrm{~Hz}$ and equipped with an amplifier rated at peak values of 40 $\mathrm{A}$ and $110 \mathrm{~V}$. The manufacturer certifies the repeatability of the measurement system at $0.5 \%$ for the magnetic field measurements and $0.2 \%$ for the power loss measurements. The accuracy and stability appears to be better than those specified in national and international standards [21-23]. The Table 2 shows the electrical and physical properties for the chosen materials that include M40050A, DI MAX-M19 and DI MAX-M15.

The Fig. 1 shows the magnetic flux density (B) - magnetic field strength $(\mathrm{H})$ curves of the chosen non oriented steels M400-50A, DI MAX-M19 and DI MAX-M15 as a function of flux swing. The magnetic field required to attain the magnetic flux density over $1.0 \mathrm{~T}$ is $131 \mathrm{~A} / \mathrm{m}$ in DI MAX-M15, while it is about $145 \mathrm{~A} / \mathrm{m}$ and $200 \mathrm{~A} / \mathrm{m}$ in DI MAX-M19 and M400-50A respectively. The difference

Table 2. Magnetic and Material Properties of Used Core Material.

\begin{tabular}{ccccc}
\hline \hline Material & $\begin{array}{c}\text { Thickness } \\
(\mathrm{mm})\end{array}$ & $\begin{array}{c}\mathrm{W} 15 / 400 \mathrm{~Hz} \\
(\mathrm{~W} / \mathrm{kg})\end{array}$ & $\begin{array}{c}\text { Density } \\
\left(\mathrm{kg} / \mathrm{m}^{3}\right)\end{array}$ & $\begin{array}{c}\text { Max. Relative } \\
\text { Permeability }\end{array}$ \\
\hline M400-50A & 0.50 & 72.4 & 7700 & 3300 \\
DI MAX-M19 & 0.35 & 41.8 & 7650 & 5600 \\
DI MAX-M15 & 0.35 & 38.2 & 7650 & 6100 \\
\hline
\end{tabular}




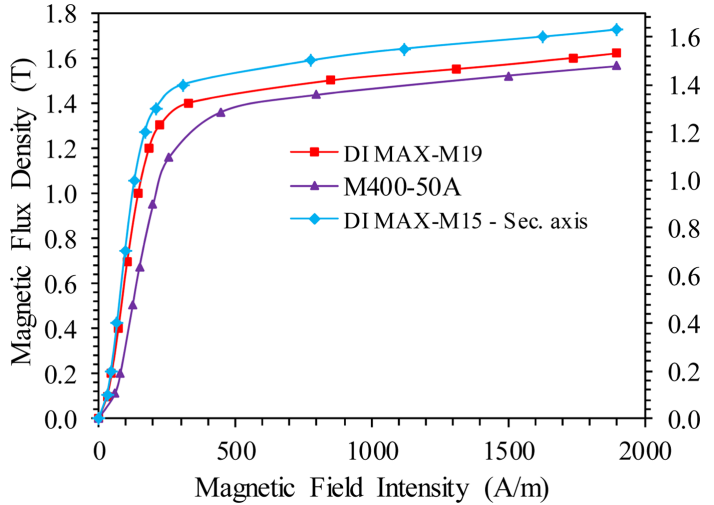

Fig. 1. (Color online) B-H characteristics of M400-50A, DI MAX-M19 and DI MAX-M15 at $400 \mathrm{~Hz}$.

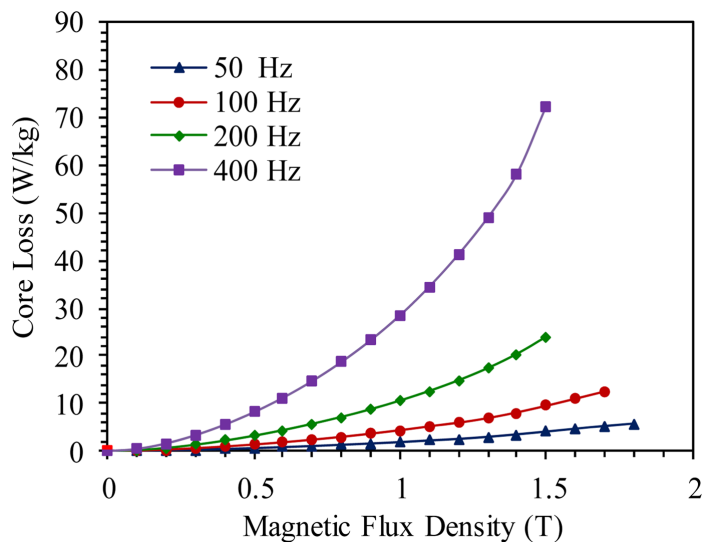

Fig. 2. (Color online) Core loss curves of M400-50A at various frequencies.

lies in the required magnetic field appears to be larger in the regions of higher magnetic flux density. It explains as to why the motor core loss with DI MAX-M15 as the core material offers a remarkable reduction in the losses

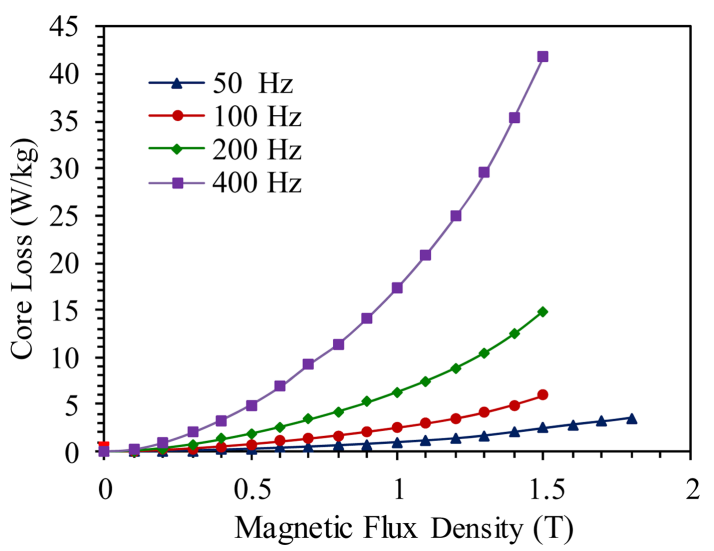

Fig. 3. (Color online) Core loss curves of DI MAX-M19 at various frequencies.

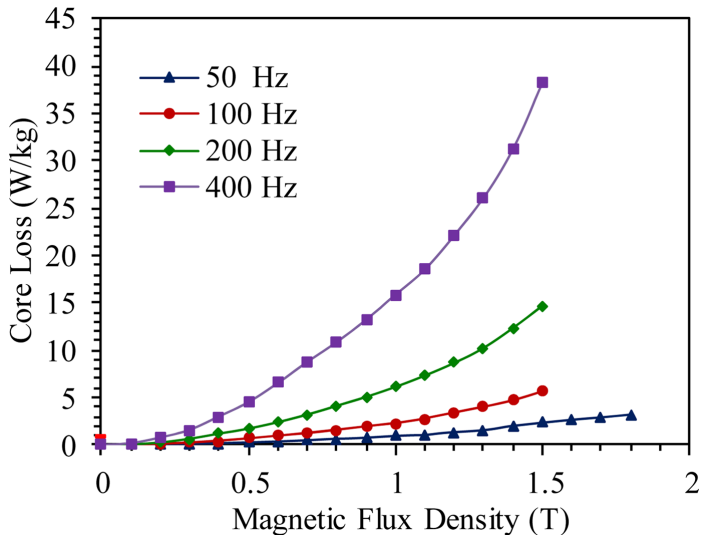

Fig. 4. (Color online) Core loss curves of DI MAX-M15 at various frequencies.

at the same operating condition.

The loss curves of non-oriented steels M400-50A, DI MAX-M19 and DI MAX-M15 drawn over the frequency range of $50 \mathrm{~Hz}-400 \mathrm{~Hz}$ as seen from Figs. 2-4 bring out the merits of the loss characteristics of the non-oriented electrical steels. It shows that the core loss of DI MAXM15 is lower by $8.6 \%$ of that of DI MAX-M19 and 47 $\%$ of M400-50A at the frequency of $400 \mathrm{~Hz}$ and flux density of $1.5 \mathrm{~T}$.

\section{Core Loss Expression and Coefficients}

The modeling of the core losses appears to be an enviable task and based on empirical equations obtained from the measurement data. Though a host of methods for determining core losses remain in vogue [24], still the models based on the Steinmetz equation and the loss separation models demand a greater focus and seem to be best suited for fast core losses estimation.

An empirical equation augurs to formulate the commonly used model for estimating the core loss [24, 25]

$$
W_{c}=K \cdot f^{\alpha} \cdot B_{m}^{\beta}
$$

Where $W_{c}$ is the core loss, $f$ the field excitation frequency and $B_{m}$ the amplitude of magnetic flux density and $K, \alpha, \beta$ refers to the material parameters. However these material parameters range their validity for a limited frequency and the magnetic flux density [24, 25]. The modifications to Eq. (1) form part of the contributions in [24] and [26]. The second method of estimating the core losses traces back to the work of Jordan [27] where the core losses separate into hysteresis loss $\left(W_{h}\right)$ and eddy current loss $\left(W_{e}\right)$

$$
W_{c}=W_{h}+W_{e}
$$


With $\alpha=1$, the hysteresis loss from Eq. (2) can be calculated from Eq. (1) and the eddy current loss from Eq. (2) can be calculated with the help of Maxwell's equations [24]

$$
W_{e}=\frac{\sigma \cdot \pi^{2} \cdot d^{2}}{6 \cdot \rho} \cdot B_{m}^{2} \cdot f^{2}
$$

Where $\sigma$ is the conductivity, $d$ is the thickness and $\rho$ is the mass density of steel lamination. The Eq. (3) derived on the homogenous condition of the magnetic material both under the consideration of similar electrical and magnetic conditions [28] follows the assumption of negligible skin effect and the hysteresis losses from Eq. (2) therefore cannot be calculated but requires to be determined by fitting the model to the measurement data.

The third method to improve Eq. (2) is to introduce the excess losses $\left(W_{e x}\right)$ [29]

$$
\begin{aligned}
W_{c} & =W_{h}+W_{e}+W_{e x} \\
& =K_{h} f\left(B_{m}\right)^{2}+K_{e}\left(f B_{m}\right)^{2}+K_{e x}\left(f B_{m}\right)^{1.5}
\end{aligned}
$$

Where, the coefficients $K_{h}$ for hysteresis loss, $K_{e}$ for eddy current loss and $K_{e x}$ for excess loss.

The Eq. (4) can be written as

$$
W_{c}=K_{1} B_{m}^{2}+K_{2} B_{m}^{1.5}
$$

From Eq. (4) and (5) $K_{1}$ and $K_{2}$ can be

$$
K_{1}=K_{h} f+K_{e} f^{2} \text { and } K_{2}=K_{e x} f^{1.5}
$$

The eddy current loss coefficient is calculated directly as

$$
K_{e}=\pi^{2} \sigma \frac{d^{2}}{6}
$$

Minimizing the quadratic form to obtain $K_{1}$ and $K_{2}$

$$
f\left(K_{1}, K_{2}\right)=\Sigma\left[W_{c i}-\left(K_{1} B_{m i}^{2}+K_{2} B_{m i}^{1.5}\right)\right]^{2}=\min
$$

Where $W_{c i}, B_{m i}$ is the $i^{t h}$ point of the data on the measured loss characteristics curve.

The other two loss coefficients are obtained as

$$
K_{h}=\frac{\left(K_{1}-K_{e} f_{0}^{2}\right)}{f_{0}} \text { and } K_{e x}=\frac{\left(K_{2}\right)}{f_{0}^{1.5}}
$$

Where $f_{o}$ is the testing frequency for loss curve. The coefficients $K_{h}$ and $K_{e x}$ are determined using curve fitting

Table 3. Core Loss Coefficients.

\begin{tabular}{cccc}
\hline \hline Material & $\mathrm{K}_{\mathrm{h}}(\mathrm{W} / \mathrm{kg})$ & $\mathrm{K}_{\mathrm{e}}(\mathrm{W} / \mathrm{kg})$ & $\mathrm{K}_{\mathrm{ex}}(\mathrm{W} / \mathrm{kg})$ \\
\hline M400-50A & $2.30 \times 10^{-2}$ & $1.21 \times 10^{-4}$ & $4.90 \times 10^{-4}$ \\
DI MAX-M19 & $2.07 \times 10^{-2}$ & $4.25 \times 10^{-5}$ & $4.52 \times 10^{-4}$ \\
DI MAX-M15 & $1.88 \times 10^{-2}$ & $3.88 \times 10^{-5}$ & $4.25 \times 10^{-4}$ \\
\hline
\end{tabular}

of the core loss data. The coefficients $K_{h}, K_{e}, K_{e x}$ as seen in Table 3 forge to be the input for calculating the core loss of the SRM based on 2D time-stepping FEM.

\section{Results and Discussion}

\subsection{Simulation}

The effort owes to explore the use of various nonoriented electrical steel for the core and examine its magnetization characteristics with a perspective to claim an appropriate choice. Among the numerous numerical methods, the FEM is the most frequently used approach for arriving at an appropriate model. The procedure performs the finite element analysis using ANSOFT Maxwell 2D to simulate the performance of a $1.5 \mathrm{~kW}, 12$ / 8 SRM. It necessitates the solution of the Maxwell's equations over each element at each time step, records the values of the flux density and thereafter calculates the core losses as a postprocessor step. Since the 2D timestepping FEM engages a larger number of time steps and a longer computation time, the mesh quality directly affects the accuracy of the calculation. The Table 4 shows the $2 \mathrm{D}$ finite element discretization meshes of the stator and the rotor finite elements.

The Figs. 5-7 show the core losses in mesh elements in the core of switched reluctance machine and reveals core loss in the stator to be higher than that in the rotor core. It further establishes that the core loss dominates around the corner of the rotor and stator poles. The variation in the losses arises due to the occurrence of the different flux peaks and the rate of change of flux $(\mathrm{dB} / \mathrm{dt})$.

The Figs. 5-10 bring out the influence of relative permeability in terms of decrease in the core loss using M400-50A and DI MAX-M19 with respect to DI MAXM15 at the operating flux density. The relative permeability in this case goes over 6100 and enables a larger reduction of the core loss in the sense the core loss reduced by $48 \%$ and $8.36 \%$ with DI MAX-M15 compared with M400-50A and DI MAX-M19.

The Table 2 depicts the density of steel laminations used and therefore the maximum core loss employing M400-50A, DI MAX-M19 and DI MAX-M15 are found to be $5.51 \times 10^{+5} \mathrm{~W} / \mathrm{m}^{3}(71.55 \mathrm{~W} / \mathrm{kg}), 3.11 \times 10^{+5} \mathrm{~W} / \mathrm{m}^{3}$

Table 4. Discretization Data.

\begin{tabular}{cc}
\hline \hline Parameter & Value \\
\hline Number of stator elements & 28362 \\
Number of rotor elements & 14181 \\
Speed & $0.05 \mathrm{~m} / \mathrm{s}$ \\
Calculation time & $1 \mathrm{~h} 25 \mathrm{~m} 37 \mathrm{~s}$ \\
\hline
\end{tabular}



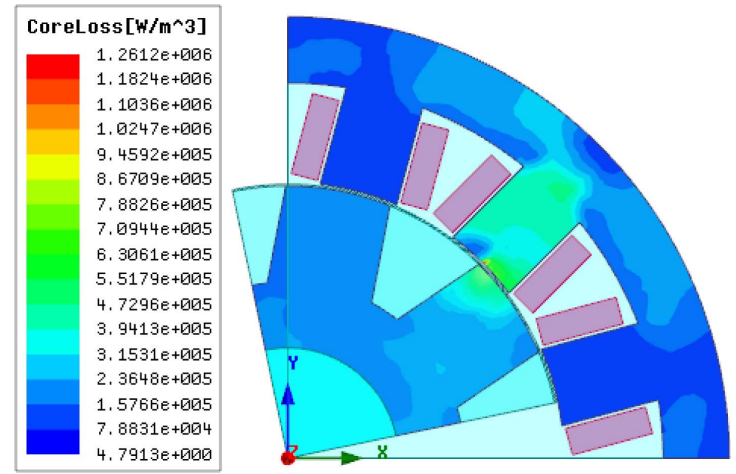

Fig. 5. (Color online) Core loss distribution of SRM using M400-50A at $400 \mathrm{~Hz}$.
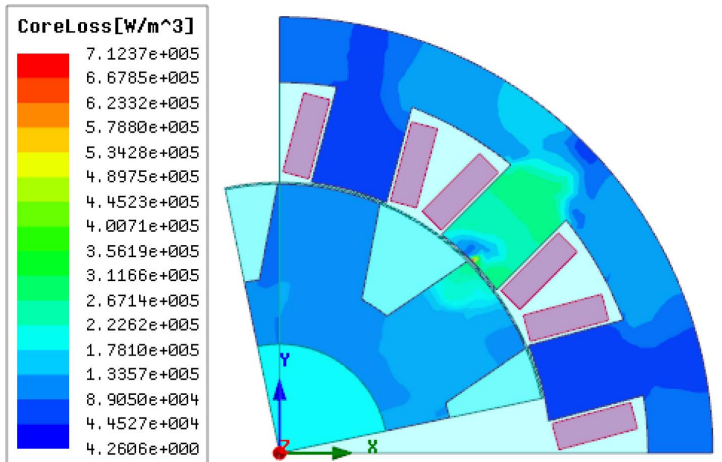

Fig. 6. (Color online) Core loss distribution of SRM using DI MAX-M19 at $400 \mathrm{~Hz}$.
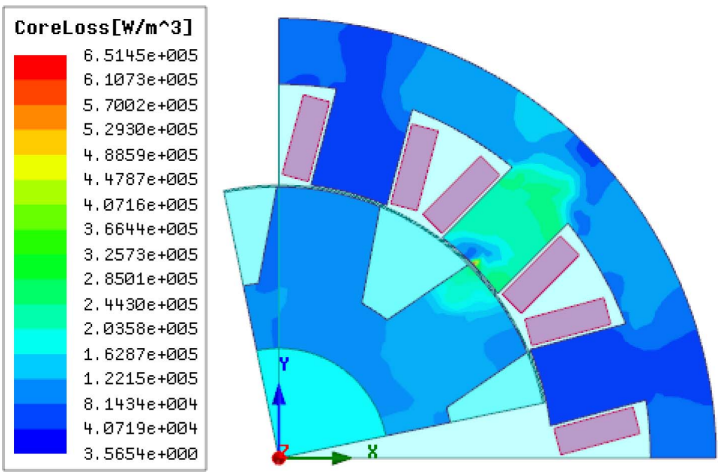

Fig. 7. (Color online) Core loss distribution of SRM using DI MAX-M15 at $400 \mathrm{~Hz}$.

$(40.65 \mathrm{~W} / \mathrm{kg})$ and $2.85 \times 10^{+5} \mathrm{~W} / \mathrm{m}^{3}(37.25 \mathrm{~W} / \mathrm{kg})$ respectively.

The core loss and steel weight of different sections are determined from the core loss model. The average core loss of SRM is

$$
W_{c S R M}=\Sigma W_{c s} \cdot m_{s}
$$

Where $W_{c s}$ and $m_{s}$ are the core loss and steel weight of various sections respectively. The core loss is $104.5 \mathrm{~W}$ for

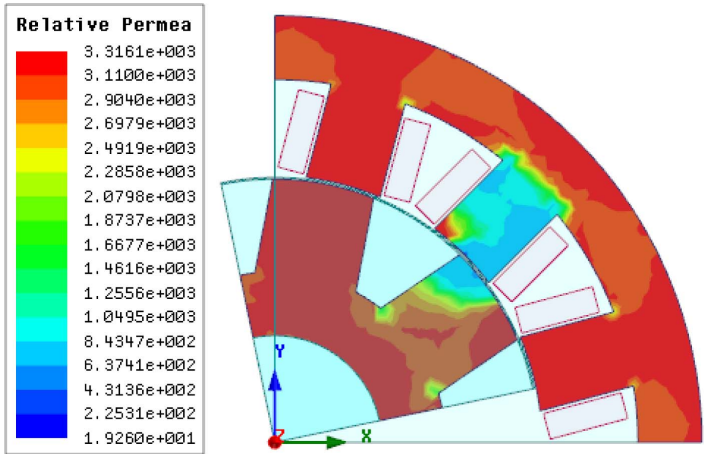

Fig. 8. (Color online) Relative permeability profile of SRM using M400-50A at $400 \mathrm{~Hz}$.

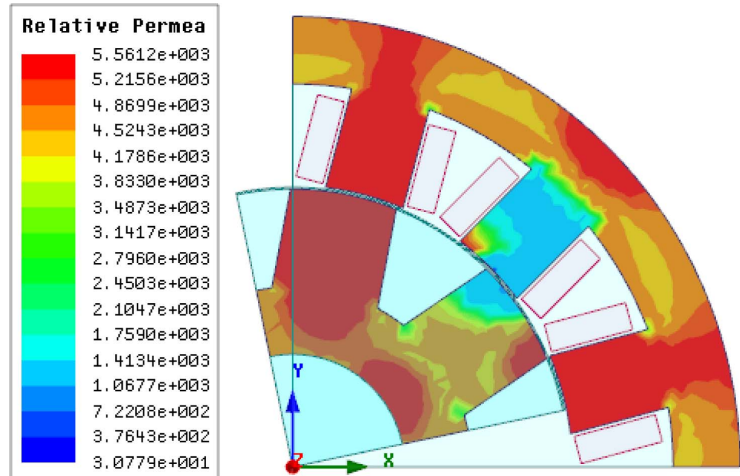

Fig. 9. (Color online) Relative permeability profile of SRM using DI MAX-M19 at $400 \mathrm{~Hz}$.

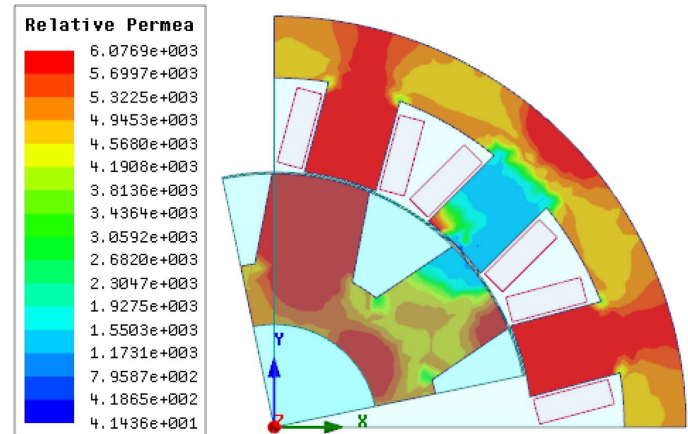

Fig. 10. (Color online) Relative permeability profile of SRM using DI MAX-M15 at $400 \mathrm{~Hz}$.

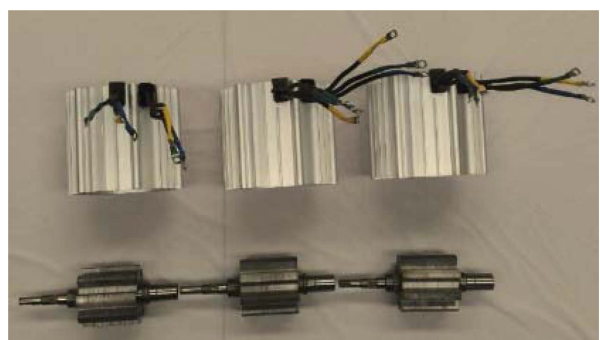

Fig. 11. (Color online) Fabricated SR motors using M40050A, DI MAX-M19 and DI MAX-M15. 
Table 5. Comparison of SRMs.

\begin{tabular}{ccccc}
\hline \hline $\begin{array}{c}\text { Material } \\
\text { of SRM }\end{array}$ & $\begin{array}{c}\text { Measured Core } \\
\text { loss }(\mathrm{W})\end{array}$ & $\begin{array}{c}\text { Simulated } \\
\text { Core loss }(\mathrm{W})\end{array}$ & $\begin{array}{c}\text { Measured Copper } \\
\text { loss }(\mathrm{W})\end{array}$ & $\begin{array}{c}\text { Simulated } \\
\text { Copper loss (W) }\end{array}$ \\
\hline M400-50A & 106.99 & 104.5 & 171.66 & 168.46 \\
DI MAX-M19 & 62.34 & 59.5 & 90.89 & 89.92 \\
DI MAX-M15 & 57.29 & 54.5 & 82.88 & 80.24 \\
\hline
\end{tabular}

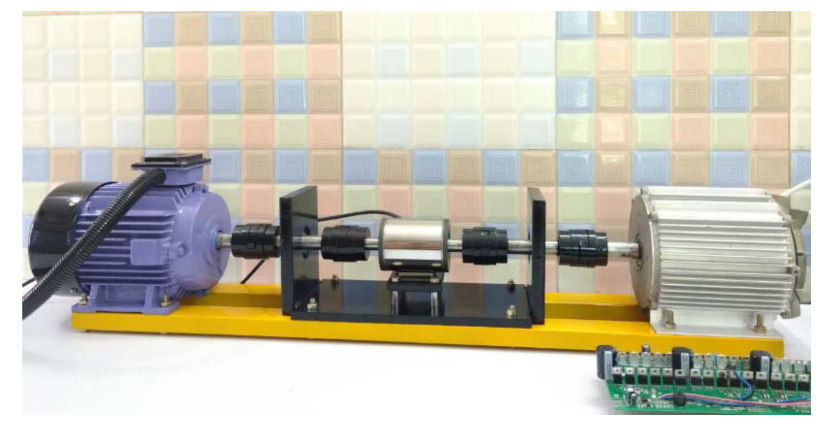

Fig. 12. (Color online) Test bench for measurement of core loss.

the M400-50A machine, 59.5 W for DI MAX-M19 machine and 54.5 W for DI MAX-M15 machine.

\subsection{Experimental set-up for loss measurement}

The Fig. 11 shows the fabricated switched reluctance motors using M400-50A, DI MAX-M19 and DI MAXM15 as a core material. The core material subdivided into thin sheets allows balancing the eddy current path resistance and induced emf shifts so that it radically reduces the overall power wastage in the core. The experimental setup shown in Fig. 12 includes an induction motor to serve as load machine for controlling the speed and measures the core loss of the SRM.

The average core loss $W_{C S R M}$ in the SRM is related using the shaft output $P_{\text {out }}$, the copper loss $W_{c u}$, the mechanical loss $W_{\text {mech }}$, and the input electric power $P_{\text {in }}$ through Eq. (11) [30]

$$
W_{c S R M}=P_{\text {in }}-P_{\text {out }}-W_{c u_{-} \text {stator }}-W_{\text {cu_rotor }}-W_{\text {mech }}
$$

The electric input power $P_{\text {in }}$ of the motor is obtained from the power meter to the motor terminals and the shaft output $P_{\text {out }}$ is calculated as the product of the measured torque and the shaft angular velocity.

The copper loss $W_{\text {custator }}$ is calculated from the rms current and the winding resistance of each phase.

Assuming the winding currents to be $I_{A}, I_{B}$, and $I_{C}$ so that

$$
W_{\text {cu_stator }}=R_{A} I_{A}^{2}+R_{B} I_{B}^{2}+R_{C} I_{C}^{2}
$$

The averaged values across the three winding resistances
$R_{A}, R_{B}$, and $R_{C}$ at an ambient temperature for each machine follow to be $0.264 \Omega$ for the M400-50A, 0.166 $\Omega$ for the DI MAX-M19 and $0.154 \Omega$ for the DI MAXM15 machine.

However in SRM the presence of the windings only on stator ensembles the rotor copper loss to be zero as seen from Eq. (13).

$$
W_{\text {cu_rotor }}=0
$$

The mechanical loss $W_{\text {mech }}$ turns out to be the product of the rotational angular velocity and the measured torque when the IM drives the shaft with no SRM excitation. The $W_{\text {mech }}$ is found to be $35.04 \mathrm{~W}$ in the M400-50A machine, $24.48 \mathrm{~W}$ for the DI MAX-M19 machine and 24.54 $\mathrm{W}$ for the DI MAX-M15 machine. The variation occurs owing to the differences in the coupling alignment and bearing conditions.

The Table 5 shows the core loss $\left(W_{c}\right)$ and copper loss $\left(W_{c u}\right)$ of the three-phase switched reluctance motor for the different core materials. The ratio of core $W_{c} / W_{c u}$ of about $1: 1.44$ to $1: 1.60$, illustrates the effect of the magnetization behavior of the different core materials.

\section{Conclusion}

The effect of non-oriented electric steel for the stator and rotor core of the SRM has been examined through both 2D-FEM simulation and using related experimental study. The material DI MAX-M15 has been borne to offer a lower core loss for the SRM and seen to adapt well with the change of motor core losses. The investigations have been portrayed to bring out the suitability of DI MAXM15 as the core material and claim a better performance for the SRM. The results have been belied to explore fresh dimensions for the use of SRM in the utility world.

\section{References}

[1] International Energy Agency website, http://www.iea.org/ etp/tracking/, 2013.

[2] T. J. E. Miller, Switched Reluctance Motors and Their Control, Clarendon, U. K, 1993.

[3] H. M. Hasanien, S. M. Muyeen, and J. Tamura, Energy 
Convers. Manage. 51, 2402 (2010).

[4] P. N. Materu and R. Krishnan, IEEE Trans. Ind. Electron. 36, 523 (1989).

[5] K. Ha and R. Krishnan, IEEE Trans. Ind. Appl. 43, 703 (2007).

[6] N. H. Fuengwarodsakul, S. Bauer, O. Tsafak, and R. W. D. Doncker, Proc. European Conference on Power Electronics and Applications, 44 (2005).

[7] K. Nakamura, T. Ono, H. Goto, T. Watanabe, and O. Ichinokura, IEEE Trans. Magn. 41, 3919 (2005).

[8] S. Inamura, T Sakai, and K. Sawa, IEEE Trans. Magn. 39, 1554 (2003).

[9] A. M. Omekanda, IEEE Trans. Ind. Appl. 39, 672 (2003).

[10] A. Chiba, Y. Takano, M. Takeno, T. Imakawa, N. Hoshi, M. Takemoto, and S. Ogasawara, IEEE Trans. Ind. Appl. 47, 1240 (2011).

[11] M. Ishida, N. Shiga, A. Honda, M. Kawano, and M. Komatsubara, Proc. 1st Japanese-Australian Joint Seminar on Applications of Electromagnetic Phenomena in Electrical and Mechanical Systems, 251 (2001).

[12] P. Beckley, Electrical Steels for Rotating Machines, The Institution of Engineering and Technology, London, 2002.

[13] H. A. Davies, F. Fiorillo, S. Flohrer, K. Guenther, R. Hasegawa, J. Sievert, L. Varga, and M. Yamaguchi, J. Magn. Mater. 320, 2411 (2008).

[14] H. Toda, K. Senda, S. Morimoto, and T. Hiratani, IEEE Trans. Magn. 49, 3850 (2013).
[15] E. El-Kharashi, Energy Convers. Manage. 48, 2261 (2007).

[16] A. Parsapour, B. M. Dehkordi, and M. Moallem, J. Magn. Mater. 378, 118 (2015).

[17] Y. Qiang, C. Laudensack, and D. Gerling, International Conference on Electrical Machines and Systems, 1 (2011).

[18] G. J. Li, J. Ojeda, E. Hoang, M. Lecrivain, and M. Gabsi, IEEE Trans. Magn. 47, 839 (2011).

[19] A. Belahcen and A. Arkkio, IET Electr. Power Appl. 4, 259 (2010).

[20] AK Steels USA, http//: www.aksteel.com/pdf/markets_products/electrical/non_oriented bulletin.pdf, 2003.

[21] BIS 649-97, Bureau of Indian Standards, New Delhi, 1997.

[22] ASTM A343-97, American Society for Testing and Materials, West Conshohocken, 2000.

[23] IEC 60404-2, Third ed., ICS 20.030, 2008.

[24] A. Krings and J. Soulard, J. Electr. Engg. 10, 162 (2010).

[25] J. Mühlethaler, J. Biela, J. W. Kolar, and A. Ecklebe, IEEE Trans. Power. Electron. 27, 953 (2012).

[26] J. Reinert, A. Brockmeyer, and R. D. Doncker, IEEE Trans. Ind. Electron. 37, 1055 (2001).

[27] H. Jordan, Elektr. Nach. Techn. 1, 7 (1924).

[28] W. A. Pluta, Electr Rev. 87, 37 (2011).

[29] J. Fang and S. Xu, IEEE Trans. Magn. 51 (2015).

[30] H. Hayashi, K. Nakamura, A. Chiba, T. Fukao, K. Tungpimolrut, and D. G. Dorrell, IEEE Trans. Energy Convers. 24, 819 (2009). 